\title{
Cenderitide, a novel dual GC-A and GC-B receptor activator, is a potent chronic cardiorenal fibroinhibiting peptide which suppresses aldosterone and reduces proteinuria in models of ardiorenal fibrosis
}

\author{
Fernando L Martin ${ }^{*}$, Paul M McKie, Jeson S Sangaralingham, Tomoko Ichiki, Gerald E Harders, Horng H Chen, \\ John C Burnett Jr
}

From 5th International Conference on cGMP: Generators, Effectors and Therapeutic Implications Halle, Germany. 24-26 June 2011

\section{Background}

Cenderitide, also known as CD-NP, is a novel Mayo engineered designer natriuretic peptide (NP), which unlike native ANP, BNP and CNP co-activates both the guanylyl (GC)-A receptor to which ANP and BNP bind and GC-B to which CNP binds. Recognizing the aldosterone suppressing actions of GC-A activation and the potent inhibition of collagen synthesis and proliferation on fibroblasts to GC-B activation we hypothesized cenderitide would be a potent anti-fibrotic therapeutic agent. Here we defined the actions of chronic cenderitide administrated subcutaneously by pump in two models of cardiorenal fibrosis which included in a model of post myocardial infarction (MI) induced cardiorenal fibrosis and also in a model of chronic kidney disease produced by uninephrectomy (UNX).

\section{Methods}

Cenderitide was administered for 2 weeks $(170 \mathrm{ng} / \mathrm{kg} /$ min, Nile Therapeutics) with an osmotic pump following MI $(n=10)$ or UNX $(n=10)$ while the control groups received vehicle. Cardiorenal function and structure were assessed 3 to 4 weeks after MI or UNX.

\section{Results}

Cardiorenal fibrosis was markedly suppressed by cenderitide in both models of fibrosis. Specifically, following MI,

* Correspondence: martin.fernando@mayo.edu

Cardiorenal Research Laboratory, Mayo Clinic, Rochester, MN, USA collagen content was decreased in the LV (MI: $5 \pm 0.6, \mathrm{CD}$ $\mathrm{NP}: 3.5 \pm 0.4 \%, \mathrm{p}<0.05)$, and also in the renal cortex and medulla (MI:3.5 \pm 0.5 , CD-NP:1.3 $\pm 0.3, \mathrm{p}=0.002$ and MI:19 \pm 5 vs CD-NP:1.2 $\pm 0.3 \%, \mathrm{p}=0.0006)$. After UNX, CD-NP suppressed LV fibrosis vs. UNX (UNX: $4.2 \pm 0.5$, CD-NP:3 $\pm 0.4 \%, \mathrm{p}<0.05)$ and reduced medullary fibrosis. CD-NP reduced aldosterone in the MI group (MI:39.4 \pm 10 , CDNP: $15 \pm 1 \mathrm{dl} / \mathrm{ml}, \mathrm{p}=0.036$ ) as well in the $\mathrm{UNX}$ group (UNX: $30.4 \pm 6$, CD-NP: $12.6 \pm 1.8 \mathrm{ng} / \mathrm{dL}, \mathrm{p}<0.05$ ). Importantly, proteinuria was also significantly reduced in CD$\mathrm{NP}(\mathrm{p}<0.001)$ in both the MI and UNX group.

\section{Conclusion}

Cenderitide is a novel designer NP that acts as a potent cardiorenal fibro-inhibiting therapeutic agent. It inhibits cardiorenal fibrosis, suppresses aldosterone and reduces proteinuria in two models of cardiorenal fibrosis. These studies support chronic SQ CD-NP as an innovative anti-fibrotic therapeutic.

Published: 1 August 2011

doi:10.1186/1471-2210-11-S1-P22

Cite this article as: Martin et al:: Cenderitide, a novel dual GC-A and GC$B$ receptor activator, is a potent chronic cardiorenal fibroinhibiting peptide which suppresses aldosterone and reduces proteinuria in models of ardiorenal fibrosis. BMC Pharmacology 2011 11(Suppl 1):P22. 